\title{
N-Methyl-D-Aspartate Antagonists and Steroids for the Prevention of Persisting Post-Surgical Pain After Thoracoscopic Surgeries: A Randomized Controlled, Factorial Design, International, Multicenter Pilot Trial
}

This article was published in the following Dove Press journal:

Journal of Pain Research

Harsha Shanthanna, (D)

Alparslan Turan, ${ }^{2}$ Jessica Vincent, ${ }^{3}$ Remie Saab, ${ }^{2}{ }^{2}$ Yaron Shargall, ${ }^{4}$

Turlough O'Hare,'

Kimberly Davis, (1) ${ }^{5}$

Sylvanus Fonguh, ${ }^{3}$

Kumar Balasubramaniam, ${ }^{3}$

James Paul, ' lan Gilron, (iD)

Henrik Kehlet, $\mathbb{D}^{7}$

Daniel I Sessler, (ID) ${ }^{2}$

Mohit Bhandari, ${ }^{8}$ Lehana Thabane, ${ }^{9}$

PJ Devereaux (iD ${ }^{9}$

'Department of Anesthesia, McMaster University, Hamilton, ON, Canada;

${ }^{2}$ Department of Outcomes Research, Anesthesiology Institute, Cleveland Clinic,

Cleveland, OH, USA; ${ }^{3}$ Population Health

Research Institute, Hamilton, ON, Canada;

${ }^{4}$ Department of Surgery, St Joseph's Healthcare Hamilton, Hamilton, ON,

Canada; ${ }^{5}$ Acute Pain Service, St. Joseph Healthcare Hamilton, Hamilton, ON,

Canada; ${ }^{6}$ Departments of Anesthesiology and Perioperative Medicine, Biomedical and Molecular Sciences, Centre for Neuroscience Studies and School of Policy Studies, Queen's University, Kingston, ON, Canada; ${ }^{7}$ Section of Surgical Pathophysiology, Rigshospitalet, Copenhagen, Denmark; ${ }^{8}$ Department of Surgery, McMaster University, Hamilton, ON, Canada; ' $D$ Department of Health Research Methods, Evidence, and Impact, McMaster University, Hamilton, ON, Canada

Correspondence: Harsha Shanthanna Department of Anesthesia, McMaster University, 1280 Main St. W., Hamilton, Ontario L8S 4KI, Canada

Tel $+\mid$ 905-525-9|40 ext. 21737

$\mathrm{Fax}+1$ 905-523-1224

Email shanthh@mcmaster.ca
Purpose: We conducted a feasibility $2 \times 2$ factorial trial comparing N-methyl-D-aspartate (NMDA) antagonists (intravenous ketamine and oral memantine) versus placebo and intravenous steroids versus placebo, in patients having elective video-assisted thoracic surgery lobectomies, at St. Joseph's Hamilton, Canada, and Cleveland Clinic, Cleveland, USA. Our feasibility objectives were: 1) recruitment rate/week; 2) recruitment of $\geq 90 \%$ of eligible patients; and 3) $>90 \%$ follow-up. Secondary objectives were incidence and intensity of persistent post-surgical pain (PPSP) and other clinical and safety outcomes.

Methods: Using computerized randomization, patients were allocated to one of four groups: NMDA active with steroid placebo; NMDA placebo with steroid active; both NMDA and steroid active; both NMDA and steroid placebo. Patients, health providers, and data analysts were blinded to allocation. Patients were followed for 3 months after randomization.

Results: The trial was initiated in May 2017 at Hamilton and, after subsequent regulatory and ethics approval, in April 2018 at Cleveland. The trial had to be stopped after only 1 month of recruitment in Cleveland because the packaged study medications (memantine) expired and we were unable to procure the dosage required. Among 41 eligible patients, 27 (66\%) were randomized. The recruitment rate/week was $0.63,95 \%$ confidence interval $(\mathrm{CI}): 0.47-0.79$ in Hamilton; and 1, 95\% CI: $0.83-1.17$ in Cleveland. Follow-up was complete for all 24 patients $(100 \%)$ in Hamilton, and 3 of 4 patients in Cleveland. In total, only 4 patients $(15 \%)$, and 2 patients $(7 \%)$ had persistent pain at rest and with movement, respectively. There were no significant differences between groups for other outcomes.

Conclusion: The trial had to be stopped prematurely due to non-availability of study medications. Trial feasibility objectives of recruiting $90 \%$ of eligible patients and recruiting at least one patient/week per site were not met. Consideration for protocol changes will be necessary for the full trial.

Trial Registration: NCT02950233.

Keywords: persisting pain, chronic pain, prevention, NMDA antagonists, steroids, ketamine

\section{Introduction}

\section{Burden of the Problem and Etiological Considerations}

Persistent post-surgical pain (PPSP) is defined as pain that develops or increases after a surgical procedure and persists for 3 months or more. ${ }^{1}$ It is known to affect $10-50 \%$ of the surgical population. ${ }^{2,3}$ The incidence of PPSP after thoracic surgeries is as high as 
25-60\%. ${ }^{4}$ Video-assisted thoracoscopic surgeries (VATS) are assumed to have a lower incidence of PPSP compared to open thoracic surgeries; however, the existing literature is limited. $^{5-7}$ The consequences of PPSP include physical and emotional suffering, leading to chronic pain, disability, poor quality of life, and increased health costs. ${ }^{8}$ Presently, there is no established effective method of preventing PPSP after thoracic surgery. The factors contributing to the high incidence of PPSP after thoracic surgeries are not entirely clear. It is likely that several surgical and patient factors independently influence the development of PPSP. Tissue injury leads to changes in peripheral and central sensitization, further leading to the development of pathological, persistent pain due to neuroplasticity. ${ }^{9}$ Thoracic surgeries are also known to cause neuropathic pain, either due to direct nerve injury ${ }^{10,11}$ or due to subclinical changes of neuro-inflammation. ${ }^{10,12}$

\section{Study Interventions}

Ketamine acts by blocking N-methyl-D-aspartate (NMDA) receptors via a non-competitive mechanism. ${ }^{13}$ At subanesthetic doses (1-6 $\mathrm{mcg} / \mathrm{kg} / \mathrm{min})$, ketamine can have antihyperalgesic effects without significant cardiovascular and respiratory adverse effects. ${ }^{14,15}$ Memantine is an oral NMDA receptor antagonist that blocks the sustained activation of the receptor, ${ }^{16}$ and its use after ketamine infusion may facilitate sustained NMDA blockade during acute to persistent pain transition. ${ }^{17}$ Based on the available evidence, use of ketamine and memantine has the potential to decrease the chances of PPSP. ${ }^{18,19}$ Steroids are potent antiinflammatory agents affecting both inflammatory and immune pathways. ${ }^{20,21}$ Among the commonly used agents, dexamethasone is nearly five times as potent as methylprednisolone and has a biological half-life of 36-72 $\mathrm{hrs}^{20}$ Although the potential for steroids to modify PPSP exists, $^{2,22,23}$ it has not been well studied. ${ }^{18}$ No study has attempted to evaluate the effect of two doses of a longacting steroid in moderate doses.

\section{Summary}

PPSP after VATS lobectomy is an important health problem with no established method of prevention. Use of NMDA antagonists and steroids may prevent the development of PPSP. Since these agents act through different biological mechanisms, and we are unaware of any biological reason for any negative interaction, it is appropriate to study their effects in a factorial design to increase efficiency. This pilot trial was proposed to establish the feasibility of a large multicenter trial.

\section{Objectives}

Our feasibility objectives included determining the feasibility of recruiting eligible patients and patients completing the 3-month follow-up. Our clinical objectives included determining the effect of NMDA antagonists and intravenous (IV) steroids in patients having VATS lobectomies on the: 1) incidence of PPSP with movement 3 months after randomization; 2) intensity of PPSP at rest and with movement at 3 months after randomization; 3) rate of change of postoperative pain intensity over time; 4) use of narcotic analgesic medication $>3$ days/weeks beyond 4 weeks after randomization; 5) presence of neuropathic pain; 6) incidence of pain interfering with the activities of daily living; 7) thoracic surgery-specific activity limitations; 8) change in global health status; 9) quality of life; and 10) incidence of adverse effects.

\section{Materials and Methods}

The PAIN-STOP pilot trial was a multicenter randomized controlled trial (RCT) using a $2 \times 2$ factorial design to evaluate NMDA antagonists versus placebo, and dexamethasone versus placebo. Randomization was stratified by site. Patients, health care providers, data collectors, outcome adjudicators, and investigators were blinded to treatment allocation. The trial was conducted in two centers: St Joseph's Hospital, Hamilton, Ontario, Canada, and Cleveland Clinic, Cleveland, Ohio, USA. The trial was registered at ClinicalTrials.gov and received ethics approval at both sites before trial initiation. This trial was conducted according to the Declaration of Helsinki, and all participants provided written, informed consent.

\section{Patient Selection}

Inclusion and exclusion criteria: Patients were eligible if they were between 18 and 65 years of age, were scheduled for elective VATS pulmonary lobectomy, and provided informed consent to participate. Patients were excluded if they met one or more of the following criteria: not willing to participate; existing pain on the same side of the chest of moderate to severe intensity $(>3 / 10$ in $0-10 \mathrm{NRS}$, where $0=$ no pain and $10=$ maximum pain); current history of intracranial mass or cerebral aneurysm or raised intraocular pressure; glomerular filtration rate $<30 \mathrm{~mL} / \mathrm{min}$ based on creatinine clearance; known allergies to one or more of the study medications; history of steroid treatment $>10 \mathrm{mg}$ /day of prednisolone or its equivalent for $>3$ weeks within the 3 months before randomization; history 
of schizophrenia or bipolar disorder; current history of drug addiction (prescription or non-prescription drug addiction diagnosed by a physician, excluding alcohol); pregnancy; and previous participation in the PAIN-STOP trial.

Eligible patients were identified from the thoracic surgery operating room booking list and approached by the research personnel during their pre-surgical consult. To provide study information and to enhance patient participation, patients were provided with an information brochure (Appendix 1) about postoperative pain and its treatment. Patients fulfilling the selection criteria were consented. Study personnel collected baseline information including patient demographics, smoking history, diagnosis, and history of radiation or chemotherapy. The following additional baseline information was collected from each consenting patient: 1) Hospital Anxiety and Depression Scale; ${ }^{24}$ 2) Pain Catastrophizing Scale; ${ }^{25} 3$ ) pain elsewhere in the body and its severity; and 4) the use of any ongoing analgesic medications.

\section{Assignment of Interventions}

Randomization was performed before surgery via an Interactive Web Randomization System (IWRS) maintained at the coordinating center at the Population Health Research Institute, McMaster University in Hamilton, Ontario, Canada. Patients were randomized using block randomization stratified by center, in a $1: 1: 1: 1$ fashion to receive, 1) NMDA active and dexamethasone placebo; 2) dexamethasone active and NMDA placebo; 3) NMDA active and dexamethasone active; or 4) NMDA placebo and dexamethasone placebo. Patients, health care providers, data collectors, data analysts, and outcome adjudicators were masked to treatment allocation. The research personnel obtained the masked study medication kit from the hospital pharmacy, and delivered it to the anesthesiologist, and the nursing staff who provided these drugs to the patients in the hospital.

\section{Study Interventions}

NMDA antagonist treatment included active ketamine administered at $0.5 \mathrm{mg} / \mathrm{kg}$ as an IV bolus during induction, and $0.1 \mathrm{mg} / \mathrm{kg} / \mathrm{hr}$ IV infusion starting in the post-anesthetic care unit, and continuing up to $24 \mathrm{hrs}$ or until discharge from a monitored bed. Placebo ketamine $(0.9 \%$ normal saline solution) was administered by infusion at the same rate and duration as above. Starting on the $1^{\text {st }}$ postoperative day, oral memantine (or matching placebo) was self-administered at $5 \mathrm{mg}$ BID for the $1^{\text {st }}$ week and increased to $10 \mathrm{mg}$ BID starting in week 2, and continued until the end of 4 weeks after surgery. The steroid intervention involved $25 \mathrm{mg}$ of IV dexamethasone administered in a $50 \mathrm{~mL}$ normal saline bag, post-induction before incision, and on the morning of postoperative day 2. For patients allocated to placebo, $50 \mathrm{~mL}$ of saline was administered at the same time points.

\section{Monitoring and Safety of Ketamine Administration}

As necessitated by the hospital policy and as suggested by the existing guidelines, study patients were observed in a high dependency bed (step down unit) and monitored for respiratory rate, continuous electrocardiogram, blood pressure, sedation level, oxygen saturation, and pain scores. ${ }^{26}$ Infusion of ketamine or placebo was titrated to side effects such as disorientation, dystonia, sedation, hallucination, nightmares, and delirium. Observation of one or more of the above side effects required stopping the infusion until the side effect resolved and restarting at half the dose rate. If the same side effect occurred again the infusion was discontinued. The reason for decreasing the concentration or stopping the infusion was noted.

\section{Surgical Protocol}

All study patients were planned to have elective VATS lobectomy under general anesthesia using appropriate IV induction and inhalational medications. Intraoperative analgesia was provided using IV opioids, with or without IV ketorolac 15-30 mg, as decided appropriate by the treating anesthesiologist. All patients had continuous electrocardiogram, oxygen saturation, intra-arterial blood pressure, and urinary catheter monitoring, as required by local standard practices. At the end of surgical procedure, all patients had local anesthetic infiltration to sites of trochar insertion, and intercostal block above and below the site of chest tube insertions with $0.25 \%$ bupivacaine with or without adrenaline. The anesthesiologist administered the study medications. In the event of conversion of VATS to open procedure, the study drug administration continued. For these patients, decision on the intraoperative placement of paravertebral catheter or postoperative placement of thoracic epidural catheter was done on a case-by-case basis, as per the decision of the involved surgeon and the anesthesiologist. Analgesia was provided with opioidbased patient-controlled analgesia (PCA) along with nonsteroidal anti-inflammatory drugs (NSAIDs). 


\section{Post-Discharge Care}

Patients continued with their regular prescription medications that they had before surgery along with study medications continued up to 1 month. For the first 2 weeks, postdischarge analgesia included around-the-clock NSAIDs plus moderate-strength opioids, such as codeine plus acetaminophen or oxycodone plus acetaminophen, for regular and breakthrough pain. Following this, analgesic prescriptions were made based on an individual patient's need. Use of opioid analgesia was recorded in a pain diary and follow-up phone calls. Patients were not allowed the use of other atypical analgesics such as antidepressants or gabapentinoids, unless patients had been on these medications before surgery. For patients with PPSP at 3 months, referral arrangements for the assessment and management of persistent pain at the respective hospital's chronic pain clinic were made.

\section{Patient Follow-Up}

Study personnel followed patients daily in the hospital and ensured compliance with study medications and recorded outcomes. Patients were contacted by phone on day 8 , and 2 months post-randomization. Patients completed a diary with daily recording of drug intake, pain scores, and analgesic use for the first 30 days, and once- to thrice-weekly recording of pain scores at rest and with movement, and analgesic use from 30 days to 3 months post-randomization. Patients were encouraged to visit the hospital at the end of 1 month and 3 months post-randomization (final follow-up). Research personnel coordinated these visits with the surgeon's office to facilitate each patient attending a surgical and study follow-up on the same day. For patients unable to make a visit, a phone follow-up was arranged.

\section{Study Outcomes}

The primary (feasibility) outcomes included the ability to: 1) recruit at least four patients per month per site; 2) recruitment of $\geq 90 \%$ of eligible patients; and 3 ) obtain a follow-up in $>90 \%$ of enrolled patients at 3 months. Secondary outcomes included the primary and secondary outcomes for the main clinical trial and were collected at 3 months after randomization, unless stated otherwise. Adverse outcomes were noted as tertiary outcomes from the time of randomization up to 3 months. Blinded outcome adjudicators (expert physicians) adjudicated the outcomes of pneumonia and persistent air leak, which were used for analyses of these events.

\section{Secondary Outcomes}

1) Incidence of PPSP ( $>3 / 10$ on a $0-10$ NRS) with movement; ${ }^{27}$ 2) intensity of PPSP (ie, average NRS score during the last week); 3 ) the rate of change of postoperative pain intensity from surgery up to 3 months after randomization (pain trajectory), ${ }^{28} 4$ ) use of narcotic analgesic medication $>3$ days/week beyond 4 weeks after randomization; 5) presence of neuropathic pain (ie, $>3$ out of 7 items using Douleur Neuropathique (DN4) scale); ${ }^{29} 6$ ) difference in interference with activities of daily living measured using Brief Pain Inventory (BPI) interference score; ${ }^{27}$ 7) difference in thoracic surgery-specific activity limitations; ${ }^{30} 8$ ) global health status measured using global impression of change (GIC); ${ }^{27}$ and 9) difference in quality of life (QoL) using European Organization for Research and Treatment of Cancer (EORTC) QoL-30.. ${ }^{31}$

\section{Tertiary Outcomes}

1) Myocardial infarction; 2) myocardial injury after noncardiac surgery; ${ }^{32} 3$ ) postoperative pneumonia; 4) prolonged air-leak; 5) new intubation and positive pressure ventilation; and 6) surgical site infection.

\section{Statistical Analyses and Sample Size}

The analysis and reporting of results were performed according to CONSORT guidelines extension to pilot and feasibility RCTs. ${ }^{33}$ We analyzed patients in the treatment group to which they were allocated, according to the intention-to-treat principle, and patients lost to follow-up were censored at the time they were lost to follow-up. As a feasibility study, analysis of all clinical outcomes was exploratory. Feasibility outcomes were assessed as proportions and rates with 95\% CI. For the analysis of clinical outcomes, we compared patients allocated to "NMDA antagonists" to "NMDA placebo" and patients allocated to 'steroids' to "steroid placebo". Analysis of continuous outcomes was based on independent $t$ test and binary outcomes on logistic regression. The results on the estimates of effect are reported as mean difference for continuous outcomes and OR for binary outcomes, with corresponding 95\% CI. No interim analyses were planned. For pain trajectory, representing the change in postoperative pain over time, repeated pain measures were analyzed using a mixed effects model to obtain slope and curve for treatment and placebo groups. $^{34}$ All analyses were performed using SAS 9.4 (Cary, NC, USA). Sample size was based on feasibility considerations, ${ }^{35,36}$ with a total sample of 48 patients, 
with 12 in each group. This is considered appropriate for a pilot feasibility trial.

\section{Results}

The study was initiated at Hamilton on May 3, 2017. After obtaining subsequent Food and Drug Administration (FDA) approval we applied for ethics approval from Cleveland in September 2017 but were able to secure approval only in April 2018. After just 2 weeks of recruitment in Cleveland, we had to stop recruitment and terminate the trial, because the packaged study medications were expiring and there was no available supply of $5 \mathrm{mg}$ memantine tablets from our source. The CONSORT flow chart (Figure 1) shows the patient flow and reasons for non-inclusion. Out of 97 patients screened for eligibility, 41 were eligible and 27 were randomized (66\%), and all except one patient completed the final 3-month follow-up. The baseline characteristics of the included patients are shown in Table 1. No patients had a prior history of PPSP and scores for both anxiety and depression were high (indicative of severe rating) in all four groups. The mean dose of opioids (morphine equivalent dose per day) before surgery was similar.

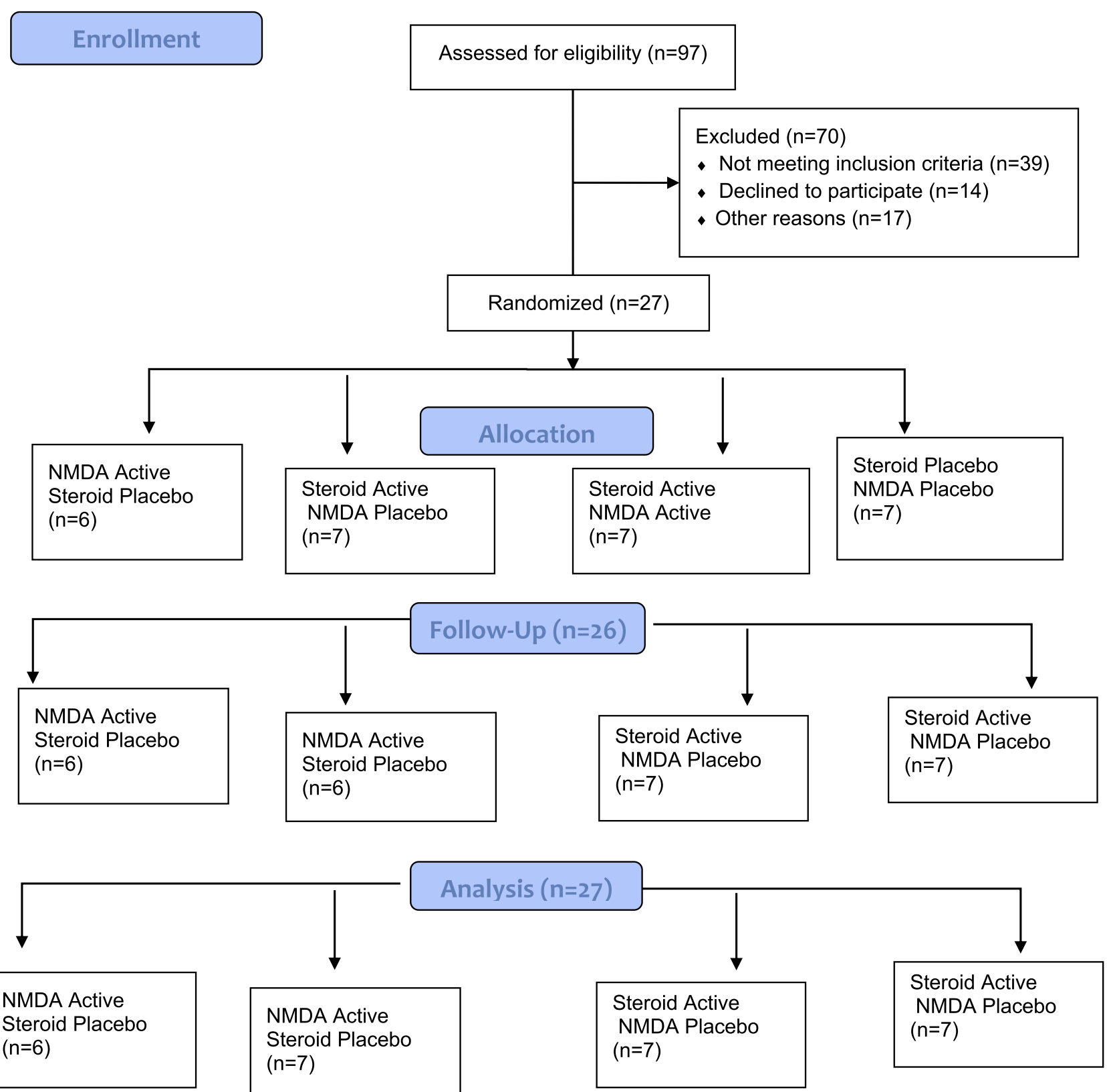

Figure I CONSORT 2010 Flow Diagram. 
Table I Baseline Characteristics of Patients

\begin{tabular}{|c|c|c|c|c|}
\hline & $\begin{array}{l}\text { NMDA Active } \\
(n=\mid 3) \text { Mean } \pm S D \\
\text { or Number }(\%)\end{array}$ & $\begin{array}{l}\text { NMDA Placebo } \\
(n=\mid 4) \text { Mean } \pm S D \\
\text { or Number }(\%)\end{array}$ & $\begin{array}{l}\text { Steroid Active } \\
(n=\mid 4) \text { Mean } \pm S D \\
\text { or Number }(\%)\end{array}$ & $\begin{array}{l}\text { Steroid Placebo } \\
(n=\mid 3) \text { Mean } \pm S D \\
\text { or Number }(\%)\end{array}$ \\
\hline Age & $65.9 \pm 6.4$ & $63.9 \pm 8.4$ & $66.4 \pm 6.4$ & $63.2 \pm 8.4$ \\
\hline Male & $6(46.2)$ & $7(50.0)$ & $5(35.7)$ & $8(61.5)$ \\
\hline BMI & $27.1 \pm 5.0$ & $30.0 \pm 5.9$ & $27.1 \pm 6.2$ & $30.2 \pm 4.7$ \\
\hline $\begin{array}{l}\text { History of chemo or radiotherapy for cancer in } \\
\text { the last } 12 \text { months }\end{array}$ & $2(15.4)$ & I (7.I) & $2(14.3)$ & I (7.7) \\
\hline History of previous chest surgery on the same side & I (7.7) & I (7.I) & I (7.I) & I (7.7) \\
\hline History of chronic pain in other parts of the body & $2(15.4)$ & $4(28.6)$ & $3(2 \mid .4)$ & $3(23.1)$ \\
\hline Prior history of PPSP & $0(0.0)$ & $0(0.0)$ & $0(0.0)$ & $0(0.0)$ \\
\hline HADS-Anxiety score & $18.2 \pm 3.4$ & $18.9 \pm 1.1$ & $18.6 \pm 2.5$ & $18.6 \pm 2.5$ \\
\hline HADS-Depression score & $15.5 \pm 1.0$ & $15.2 \pm 1.5$ & $15.2 \pm 0.9$ & $15.5 \pm 1.6$ \\
\hline Summary PCS score & $11.5 \pm 12.0$ & $12.9 \pm 13.2$ & $15.6 \pm 13.5$ & $8.9 \pm 10.8$ \\
\hline Total dose of opioids as MED per day & $5.7 \pm 2.5$ & $4.5 \pm 0.8$ & $5.7 \pm 2.5$ & $4.5 \pm 0.8$ \\
\hline
\end{tabular}

Abbreviations: BMI, body mass index; HADS, hospital anxiety and depression scale; MED, morphine dose equivalent; NMDA, N-methyl-D-aspartate; PCS, patient catastrophizing scale; SD, standard deviation.

The intraoperative and postoperative characteristics of patients are summarized in Table 2 .

The most common diagnosis was primary lung cancer. Four patients needed conversion to open in the NMDA placebo, and steroid placebo groups, and had postoperative epidural or paravertebral catheters for analgesia. A majority of patients had only one chest drain of size 28 French. The utility incision performed to extract the resected lung tissue was less than $4 \mathrm{~cm}$ in most patients. The amount of PCA opioid used was higher in placebo groups compared to their respective active groups. Number of days with chest tube and total duration of hospital stay were similar across groups. One patient who had both active interventions had myocardial injury after noncardiac surgery (MINS).

\section{Outcomes}

\section{Feasibility Outcomes}

At Hamilton, the percentage of eligible patients recruited was $65 \%$ (24/37). Out of 88 patients screened, 24 consented, and 13 refused; 30 were above the upper age limit; 15 patients were participating in a competing trial; and six were excluded (three due to known history of intracranial mass, two due to prior history of schizophrenia or bipolar disease, and one due to current pain on the same side of the chest). We only had 2 weeks of recruitment at Cleveland. Among the nine patients screened, four were eligible, and three provided consent. The recruitment rates per week (95\% CI) were $0.63(0.47-0.79)$; and 1 (0.83-1.17), respectively, at Hamilton and Cleveland. Only one patient was lost to follow-up in Cleveland, and the percentage of randomized patients with follow-up at 3 months was $100 \%$ at Hamilton.

\section{Treatment Compliance and Follow-Up}

We were able to administer study medications as per the protocol in all except one patient, as the anesthesiologist refused to administer the study medication. Only one other patient did not receive his second dose of steroid intervention. All other patients continued with their study medications.

\section{Clinical Outcomes}

At 3 months post-randomization, the number of patients who had any PPSP (resting score $>0$ in $0-10$ NRS), and PPSP on movements ( $>3$ in $0-10$ NRS) were four, and two patients, respectively. The secondary outcomes are shown in Table 3 and Figure 2 (rate of change in postoperative pain intensity), and Appendix 2 and $\underline{3}$ (global change and quality of life). There were no important differences in any outcomes.

We did not observe any influence of the study interventions on the resolution of postoperative pain intensity over time. The adjusted difference in mean intensity between treatment and placebo groups and test for interaction effect for different time points were not significant (Figure 2). The tertiary outcomes are summarized in Table 4 . There were no deaths or major adverse effects due to treatment.

\section{Discussion}

In this factorial design pilot trial comparing NMDA antagonists with placebo and steroids with placebo in VATS lobectomy patients, we were unable to demonstrate feasibility based on lower than expected recruitment rate, 
Table 2 Intraoperative and Postoperative Characteristics of Study Patients

\begin{tabular}{|c|c|c|c|c|}
\hline & $\begin{array}{l}\text { Steroid } \\
\text { Active }(n=\mid 4)\end{array}$ & $\begin{array}{l}\text { Steroid } \\
\text { Placebo }(n=13)\end{array}$ & $\begin{array}{l}\text { NMDA } \\
\text { Active }(n=13)\end{array}$ & $\begin{array}{l}\text { NMDA } \\
\text { Placebo }(n=14)\end{array}$ \\
\hline \multicolumn{5}{|l|}{ Intraoperative characteristics } \\
\hline \multicolumn{5}{|l|}{ Diagnosis - N (\%) } \\
\hline Primary lung cancer & II (78.6) & $12(92.3)$ & $12(92.3)$ & II (78.6) \\
\hline Metastasis & $3(21.4)$ & $0(0.0)$ & I (7.7) & $2(14.3)$ \\
\hline Infection & $0(0.0)$ & I (7.7) & $0(0.0)$ & I (7.I) \\
\hline \multicolumn{5}{|l|}{ Lobe resected - N (\%) } \\
\hline Upper & $8(57.1)$ & $9(69.2)$ & $10(76.9)$ & $7(50.0)$ \\
\hline Middle & $2(14.3)$ & $2(15.4)$ & $0(0.0)$ & $4(28.6)$ \\
\hline Lower & $7(50.0)$ & $4(30.8)$ & $5(38.5)$ & $6(42.9)$ \\
\hline Conversion to open - N (\%) & $2(14.3)$ & $4(30.8)$ & $2(15.4)$ & $4(28.6)$ \\
\hline \multicolumn{5}{|l|}{ Number of ports - N (\%) } \\
\hline I & I (7.I) & I (7.7) & I (7.7) & I (7.I) \\
\hline 2 & I (7.I) & $0(0.0)$ & I (7.7) & $0(0.0)$ \\
\hline 3 & $8(57.1)$ & $7(53.8)$ & $6(46.2)$ & $9(64.3)$ \\
\hline 4 & $4(28.6)$ & $3(23.1)$ & $4(30.8)$ & $3(21.4)$ \\
\hline Number of ports with rib spreader - $\mathrm{N}(\%)$ & $0(0.0)$ & $2(15.4)$ & I (7.7) & I (7.I) \\
\hline \multicolumn{5}{|l|}{ Number of chest drains - N (\%) } \\
\hline 1 & $12(85.7)$ & $9(69.2)$ & II (84.6) & $10(71.4)$ \\
\hline 2 & $2(14.3)$ & $3(23.1)$ & I (7.7) & $4(28.6)$ \\
\hline \multicolumn{5}{|l|}{ Largest chest tube size used - N (\%) } \\
\hline 24 & I (7.I) & $0(0.0)$ & I (7.7) & $0(0.0)$ \\
\hline 28 & $12(85.7)$ & II (84.6) & $10(76.9)$ & $13(92.9)$ \\
\hline Other (9) & I (7.I) & I (7.7) & I (7.7) & I (7.I) \\
\hline \multicolumn{5}{|l|}{ Length of utility incision - N (\%) } \\
\hline$<4 \mathrm{~cm}$ & $9(64.3)$ & $5(38.5)$ & $8(61.5)$ & $6(42.9)$ \\
\hline $4-8 \mathrm{~cm}$ & $5(35.7)$ & $3(23.1)$ & $3(23.1)$ & $5(35.7)$ \\
\hline$>8 \mathrm{~cm}$ & $0(0.0)$ & $2(15.4)$ & I (7.7) & I (7.I) \\
\hline \multicolumn{5}{|l|}{ Postoperative characteristics } \\
\hline ICU admissions after surgery $N(\%)$ & $0(0.0)$ & $0(0.0)$ & $0(0.0)$ & $0(0.0)$ \\
\hline Need for continuous epidural or PVB for $>6 \mathrm{hrs} N(\%)$ & I (7.I) & $3(23.1)$ & $\mathrm{I}(7.7)$ & $3(21.4)$ \\
\hline Total Opioid used with PCA as MED* - median (IQR) & $15.0(10.0-45.0)$ & $40.0(15.0-80.0)$ & $15.0(10.0-95.0)$ & $30.0(10.0-60.0)$ \\
\hline Number of days with chest tube - median (IQR) & $2.0(1.0-2.0)$ & $2.5(2.0-4.0)$ & $2.0(2.0-5.5)$ & $2.0(1.0-3.0)$ \\
\hline Peak value of troponin measured during hospital stay - median (IQR) & $17.5(2.0-32.0)$ & $3.0(3.0-7.0)$ & $17.5(3.0-32.0)$ & $3.0(2.5-5.0)$ \\
\hline Total duration of hospital stay (days) - median (IQR) & $4.0(3.0-5.0)$ & $5.0(4.0-10.0)$ & $5.0(4.0-6.0)$ & $4.0(4.0-7.0)$ \\
\hline
\end{tabular}

Abbreviations: ICU, intensive care unit; IQR, interquartile range; MED, Morphine dose equivalent; N, number; NMDA, N-methyl-D-aspartate; NRS, numerical rating scale; PCA, patient-controlled analgesia; PVB, paravertebral block.

and other logistical challenges that did not allow us to complete the full study recruitment. We also observed that our incidence of patients suffering from PPSP at 3 months was lower than previously reported; only 2 of 27 patients (7\%) fulfilled the criteria of PPSP with movement at 3 months after randomization. We also did not observe any particular effect of study interventions on postoperative pain resolution, either in direction or magnitude, except for differences in PCA opioid used during the postoperative stay in hospital (Table 2).

This feasibility trial involved significant challenges. It was planned as an international trial as we appreciated the need to involve other centers beyond Canada to recruit a relatively larger sample size for the main trial. The study interventions were not approved by the health regulatory agencies for preventing PPSP. This necessitated that we 
Table 3 Summary of Clinical Outcomes

\begin{tabular}{|l|l|l|l|l|}
\hline Outcomes (All Observed at 3 Months After Randomization Except “"”) & $\begin{array}{l}\text { Steroid } \\
\text { Active }\end{array}$ & $\begin{array}{l}\text { Steroid } \\
\text { Placebo }\end{array}$ & $\begin{array}{l}\text { NMDA } \\
\text { Active }\end{array}$ & $\begin{array}{l}\text { NMDA } \\
\text { Placebo }\end{array}$ \\
\hline Intensity of PPSP (resting pain) on a scale of 0-10 NRS, Median (IQR) & $3.0(2.0-5.0)$ & $1.0(1.0-1.0)$ & $2.0(1.0-3.0)$ & $5.0(5.0-5.0)$ \\
Incidence of PPSP with movement (> 3/10 in 0-10 NRS), N (\%) & $2(14.3)$ & $0(0.0)$ & $1(8.3)$ & $1(7.1)$ \\
*Use of narcotic analgesic medication >3 days/week beyond 4 weeks, N (\%) & $5(35.7)$ & $3(25.0)$ & $4(33.3)$ & $4(28.6)$ \\
Presence of neuropathic pain as >3/7 items using DN4 scale, N (\%) & $1(16.7)$ & $0(0.0)$ & $1(33.3)$ & $0(0.0)$ \\
Interference in activities of daily living using BPI in patients with PPSP, mean \pm SD & $2.5 \pm 2.0$ & $1.1 \pm 1.0$ & $3.7 \pm 2.4$ & $1.3 \pm 0.4$ \\
Thoracic surgery-specific activity limitations, mean \pm SD & $0.6 \pm 0.7$ & $0.2 \pm 0.2$ & $1.0 \pm 0.8$ & $0.2 \pm 0.2$ \\
\hline
\end{tabular}

Abbreviations: BPI, Brief Pain Inventory; DN, Douleur Neuropathique; IQR, interquartile range; N, number; NRS, numerical rating scale; NMDA, N-methyl-D-aspartate; PPSP, persistent post-surgical pain; SD: standard deviation

seek approval from Health Canada and FDA apart from obtaining individual site ethics approval, which needed to be coordinated with the regulatory approvals as well. The trial involved the use of memantine, a drug that is approved for use in patients with Alzheimer's disease. Its dosing recommendations include starting at $5 \mathrm{mg}$ and titrated upwards to $10 \mathrm{mg}$ twice a day over 2-4 weeks. ${ }^{37}$ However, most available preparations come as $10 \mathrm{mg}$ tablets and patients are informed to take half of the tablet for the initial $5 \mathrm{mg}$ dose, which is not appropriate for research. ${ }^{38}$ Only some companies satisfy regulatory approvals for clinical use in both Canada and the USA. ${ }^{39}$ Furthermore, acquisition, preparation, and packaging of study medications (including over-encapsulation of placebo capsules) from an appropriate company, and submission of batch certificate number are needed for regulatory approvals. Although we were able to work in parallel towards overcoming the above challenges, some procedures needed to happen in sequence and thereby

\section{A}

NRS Score at rest (Smooth)-NMDA vs. Placebo

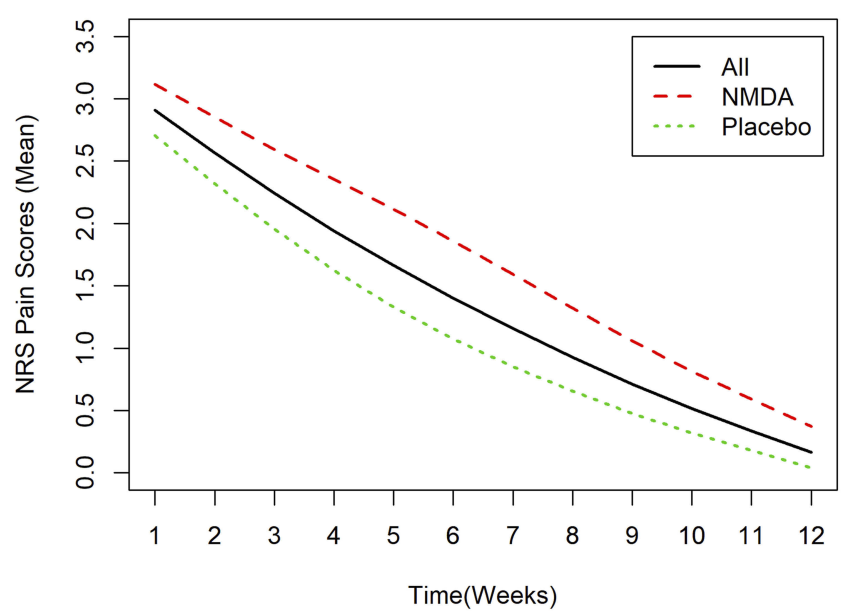

delaying trial initiation at Cleveland Clinic. Although we initiated our process of ethics approval in September 2017 at Cleveland, for reasons beyond our control, we were unable to get approval until March 2018. Finally, we were limited by the expiration of prepared study medications on April 20, 2018. Moreover, the source supplying our study medications was out of their supply of memantine $5 \mathrm{mg}$ at that time.

Besides the above-mentioned challenges, we also faced recruitment challenges in site 1 . Increased use of advanced technology provides minimally invasive options including robotic surgeries for lung resection. ${ }^{40}$ At both centers, robotic lung resection surgery was an option, and at site 1 , there was an active study comparing robotic versus VATS lobectomies that blinded patients for their procedures (https://clinicaltrials.gov/ct2/show/NCT02617186). Since our trial involved selecting patients having VATS lobectomy, we were unable to approach 15 other eligible patients as it risked unblinding for this competing trial.

B

NRS Score at rest (Smooth)-Steroids vs. Placebo

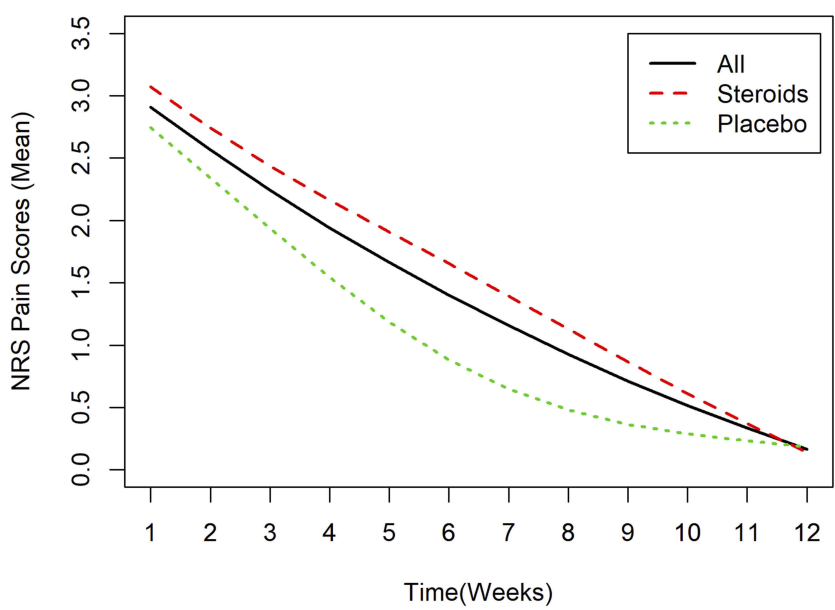

Figure 2 Rate of change in postoperative pain intensity since surgery up to 3 months after randomization. (A) Resolution of postoperative pain over time in the NMDA group; (B) Resolution of postoperative pain over time in the steroid group. 
Table 4 Summary of Tertiary Outcomes

\begin{tabular}{|c|c|c|c|c|}
\hline Outcomes & $\begin{array}{l}\text { Steroid Active } \\
\text { N (\%) }\end{array}$ & $\begin{array}{l}\text { Steroid Placebo } \\
\text { N (\%) }\end{array}$ & $\begin{array}{l}\text { NMDA Active } \\
\text { N (\%) }\end{array}$ & $\begin{array}{l}\text { NMDA Placebo } \\
\text { N (\%) }\end{array}$ \\
\hline Myocardial infarction & $0(0.0)$ & $0(0.0)$ & $0(0.0)$ & $0(0.0)$ \\
\hline Myocardial infarction after non-cardiac surgery (MINS) & I (7.7) & $0(0.0)$ & I (7.I) & $0(0.0)$ \\
\hline Postoperative pneumonia & $0(0.0)$ & I (7.I) & $0(0.0)$ & I (7.7) \\
\hline Prolonged air-leak & I (7.7) & $0(0.0)$ & $0(0.0)$ & I (7.7) \\
\hline New intubation and positive pressure ventilation & $0(0.0)$ & $0(0.0)$ & $0(0.0)$ & $0(0.0)$ \\
\hline Surgical site infection & I (7.7) & I (7.I) & I (7.I) & I (7.7) \\
\hline
\end{tabular}

Abbreviations: N, number; NMDA, N-methyl-D-aspartate

Patient recruitment for clinical trials can be challenging. ${ }^{41,42}$ In particular, recruitment for surgical trials is more unpredictable, sometimes with less than $50 \%$ recruitment rate. ${ }^{43}$ It is potentially possible that a certain degree of complexity in our trial and the need to be on study treatment for 1 month after surgery could have been a reason for some patients declining participation. In our study, appreciating the need to better inform patients about the burden of PPSP, and the importance of our study, we prepared an information brochure (Appendix 1) using layman language. Since patient consent was planned to coincide with their preoperative visit, we prioritized to identify appropriate patients before this visit, and distribute this brochure. However, we faced challenges in identifying such patients ahead of time, due to clinical demands.

Although the burden of PPSP is high with thoracic surgery, its incidence after VATS lobectomies is not consistent across studies and can vary from $22 \%$ to $63 \% .^{5,6,44}$ Based on the available literature, we estimated a lower limit of $20 \%$ incidence with movement. In our study, 30 patients were excluded based on the upper age limit of 65 years. Younger age is considered an important risk factor for PPSP. ${ }^{2,45}$ Our consideration for limiting the age at 65 years was to focus on a more susceptible population with a higher incidence of PPSP. Despite this, we observed a PPSP rate of $15 \%$ at rest and $7 \%$ with movement (clinically important PPSP). In this context, it is important to note the trial comparing VATS lobectomy versus anterolateral thoracotomy for postoperative pain and QoL. At 12-week follow-up, 8/84 (10\%), and 10/75 (13\%) patients had moderate to severe pain after VATS and thoracotomy, respectively. ${ }^{46}$ Since this is a pilot study, it is not appropriate to infer about potential treatment effects of study interventions. Studying pain trajectories in the postoperative period can provide significant information about the resolution of postoperative pain and PPSP. ${ }^{47,48}$ The existing knowledge about the transition from a state of physiologically acceptable postoperative pain into a state of PPSP is unclear. ${ }^{17}$ In our study the adjusted mean pain intensity decreased over time and by $8-9$ weeks, it was $<1$ in all patients' groups (Figure 2 ).

Although we have highlighted that there is sound rationale to test these interventions to influence the course of persisting postoperative pain, we need to acknowledge that there are limited data on the optimal dosing and timing of our study interventions to prevent PPSP. ${ }^{18}$ We used IV ketamine up to $24 \mathrm{hrs}$ after surgery, based on the need for monitored bed, and logistical considerations as many VATS lobectomy patients are moved to a non-monitored bed before $24 \mathrm{hrs}$. In comparison, a recent smaller study reported a significant risk reduction using a combination of pregabalin and ketamine, with an infusion of ketamine $(0.1 \mathrm{mg} / \mathrm{kg} / \mathrm{hr})$ for $48 \mathrm{hrs}$ after surgery in cardiac surgery patients. $^{49}$ Another review and meta-analysis looking at memantine for treating or preventing pain observed considerable variation in the dose and duration of its treatment. ${ }^{19}$ The other factors that could potentially affect the outcomes include conversion of VATS to open surgeries and the use of continuous epidural analgesia.

Despite these challenges, our trial has several merits. Firstly, it further demonstrates the need for a pilot trial before embarking on a larger surgical trial. An empirical study looking at completion and publication rates of RCTs in surgery found that nearly half (43\%) were discontinued, in comparison to $27 \%$ in medicine trials. ${ }^{50}$ Our study also highlights the limitations of assuming a relatively higher PPSP risk in VATS lobectomy population.

\section{Conclusion}

Based on our results, we believe appropriate changes to study population, such as including other populations at higher risk of PPSP along with VATS lobectomy patients, with stratification based on surgical type, should be considered to make a larger trial feasible. This could also allow the participation of other study centers. 


\section{Ethical Committee Approvals}

Ethics approval was obtained from Hamilton Integrated Research Ethics Board, \# 2305, on March 23, 2017, and IRB of Cleveland Clinic \#17-1608, on March 1, 2018.

\section{Data Sharing Statement}

Data regarding de-identified patient outcomes will be shared based on a specific request for the next 2 years.

\section{Acknowledgments}

We are thankful to Dr. Sadeesh Srinathan, Section of Thoracic Surgery, Health Sciences Centre, Winnipeg, Manitoba, Canada, and Dr. Michael McGillion, School of Nursing, Faculty of Health Sciences, McMaster University, Canada for their valuable suggestions to improve the study design. We are thankful to our research team at St. Joseph's hospital, Hamilton and Cleveland Clinic, Cleveland. We also acknowledge the support from the thoracic surgery department, and the nursing team at both centers. We thank Sara Miller M.Sc., Scientific Editor, Department of Anesthesia-Research Office, McMaster, for editing this manuscript.

\section{Funding}

2016, Michael G DeGroote Institute of Pain Research and Care grant, \$30,000 (CAD) and 2016 Carl Koller Memorial Research Grant award, American Society of Regional Anesthesia and Pain Medicine, \$50,624 (USD). Harsha Shanthanna is supported by the Canadian Anesthesia Research Foundation through the Career Scientist Award, 2018-2020.

\section{Disclosure}

Dr. Philip J. Devereaux reports grants from Abbott Diagnostics, Boehringer Ingelheim, Philips Healthcare, Roche Diagnostics, and Siemens, outside the submitted work. The authors report no other conflicts of interest in this work.

\section{References}

1. Schug SA, Lavand'homme P, Barke A, Korwisi B, Rief W, Treede RD. The IASP classification of chronic pain for ICD-11: chronic postsurgical or posttraumatic pain. Pain. 2019;160(1):45-52. doi:10.1097/j.pain.0000000000001413

2. Kehlet H, Jensen TS, Woolf CJ. Persistent postsurgical pain: risk factors and prevention. Lancet. 2006;367(9522):1618-1625. doi:10.1016/ S0140-6736(06)68700-X

3. Werner MU, Kongsgaard UEI. Defining persistent post-surgical pain: is an update required? Br J Anaesth. 2014;113(1):1-4. doi:10.1093/bja/ aeu012
4. Wildgaard K, Ravn J, Kehlet H. Chronic post-thoracotomy pain: a critical review of pathogenic mechanisms and strategies for prevention. Eur $J$ Cardiothorac Surg. 2009;36(1):170-180. doi:10.1016/j.ejcts.2009. 02.005

5. Gottschalk A, Cohen SP, Yang S, Ochroch EA. Preventing and treating pain after thoracic surgery. Anesthesiology. 2006;104 (3):594-600. doi:10.1097/00000542-200603000-00027

6. Pluijms WA, Steegers MA, Verhagen AF, Scheffer GJ, Wilder-Smith OH. Chronic post-thoracotomy pain: a retrospective study. Acta Anaesthesiol Scand. 2006;50(7):804-808. doi:10.1111/aas.2006.50. issue-7

7. Steegers MA, Snik DM, Verhagen AF, van der Drift MA, WilderSmith OH. Only half of the chronic pain after thoracic surgery shows a neuropathic component. J Pain. 2008;9(10):955-961. doi:10.1016/ j.jpain.2008.05.009

8. Gureje O, Von Korff M, Simon GE, Gater R. Persistent pain and well-being: a World Health Organization Study in primary care. JAMA. 1998;280(2):147-151. doi:10.1001/jama.280.2.147

9. Woolf CJ. Central sensitization: implications for the diagnosis and treatment of pain. Pain. 2011;152(3 Suppl):S2-S15. doi:10.1016/j. pain.2010.09.030

10. Treede RD, Jensen TS, Campbell JN, et al. Neuropathic pain: redefinition and a grading system for clinical and research purposes. Neurology. 2008;70(18):1630-1635. doi:10.1212/01.wnl.0000282763.29778.59

11. Haroutiunian S, Nikolajsen L, Finnerup NB, Jensen TS. The neuropathic component in persistent postsurgical pain: a systematic literature review. Pain. 2013;154(1):95-102. doi:10.1016/j.pain.2012.09.010

12. Ellis A, Bennett DL. Neuroinflammation and the generation of neuropathic pain. Br J Anaesth. 2013;111(1):26-37. doi:10.1093/bja/aet128

13. Orser BA, Pennefather PS, MacDonald JF. Multiple mechanisms of ketamine blockade of N-methyl-D-aspartate receptors. Anesthesiology. 1997;86(4):903-917. doi:10.1097/00000542-199704000-00021

14. Mathews TJ, Churchhouse AM, Housden T, Dunning J. Does adding ketamine to morphine patient-controlled analgesia safely improve post-thoracotomy pain?. Interact Cardiovasc Thorac Surg. 2012;14 (2):194-199.

15. Wang L, Johnston B, Kaushal A, Cheng D, Zhu F, Martin J. Ketamine added to morphine or hydromorphone patient-controlled analgesia for acute postoperative pain in adults: a systematic review and meta-analysis of randomized trials. Can J Anaesth. 2016;63 (3):311-325. doi:10.1007/s12630-015-0551-4

16. Kumar S. Memantine: pharmacological properties and clinical uses. Neurol India. 2004;52(3):307-309.

17. Katz J, Seltzer Z. Transition from acute to chronic postsurgical pain: risk factors and protective factors. Expert Rev Neurother. 2009;9 (5):723-744. doi:10.1586/ern.09.20

18. Chaparro LE, Smith SA, Moore RA, Wiffen PJ, Gilron I. Pharmacotherapy for the prevention of chronic pain after surgery in adults. Cochrane Database Syst Rev. 2013;7:CD008307.

19. Kurian R, Raza K, Shanthanna H. A systematic review and meta-analysis of memantine for the prevention or treatment of chronic pain. Eur J Pain. 2019;23:1234-1250. doi:10.1002/ejp.1393

20. Becker DE. Basic and clinical pharmacology of glucocorticosteroids. Anesth Prog. 2013;60(1):25-31; quiz 2. doi:10.2344/0003-300660.1 .25

21. Rhen T, Cidlowski JA. Antiinflammatory action of glucocorticoids-new mechanisms for old drugs. $N$ Engl J Med. 2005;353(16):1711-1723. doi:10.1056/NEJMra050541

22. Lunn TH, Kehlet H. Perioperative glucocorticoids in hip and knee surgery - benefit vs. harm? A review of randomized clinical trials. Acta Anaesthesiol Scand. 2013;57(7):823-834. doi:10.1111/aas.2013. 57.issue-7

23. Lunn TH, Kristensen BB, Andersen LO, et al. Effect of high-dose preoperative methylprednisolone on pain and recovery after total knee arthroplasty: a randomized, placebo-controlled trial. $\mathrm{Br} J$ Anaesth. 2011;106(2):230-238. doi:10.1093/bja/aeq333 
24. Kazemi H, Ghassemi S, Fereshtehnejad SM, Amini A, Kolivand PH, Doroudi T. Anxiety and depression in patients with amputated limbs suffering from phantom pain: a comparative study with non-phantom chronic pain. Int J Prev Med. 2013;4(2):218-225.

25. Carriere JS, Thibault P, Milioto M, Sullivan MJ. Expectancies mediate the relations among pain catastrophizing, fear of movement, and return to work outcomes after whiplash injury. J Pain. 2015;16 (12):1280-1287. doi:10.1016/j.jpain.2015.09.001

26. Nova Scotia Health Authority. Ketamine for adjunct analgesia, medication manual 2015. Available from: http://policy.nshealth.ca/Site Published/dha9/document_render.aspx?documentRender.IdType= $6 \&$ documentRender.GenericField=\&documentRender.Id=57824. Accessed January 31, 2020.

27. Dworkin RH, Turk DC, Farrar JT, et al. Core outcome measures for chronic pain clinical trials: IMMPACT recommendations. Pain. 2005;113(1-2):9-19. doi:10.1016/j.pain.2004.09.012

28. Chapman CR, Donaldson GW, Davis JJ, Bradshaw DH. Improving individual measurement of postoperative pain: the pain trajectory. J Pain. 2011;12(2):257-262. doi:10.1016/j.jpain.2010.08.005

29. Bouhassira D, Attal N, Alchaar H, et al. Comparison of pain syndromes associated with nervous or somatic lesions and development of a new neuropathic pain diagnostic questionnaire (DN4). Pain 2005;114(1-2):29-36. doi:10.1016/j.pain.2004.12.010

30. Ringsted TK, Wildgaard K, Kreiner S, Kehlet H. Pain-related impairment of daily activities after thoracic surgery: a questionnaire validation. Clin J Pain. 2013;29(9):791-799. doi:10.1097/AJP.0b013e318278d4e2

31. Balduyck B, Hendriks J, Lauwers P, Van Schil P. Quality of life after lung cancer surgery: a prospective pilot study comparing bronchial sleeve lobectomy with pneumonectomy. J Thorac Oncol. 2008;3 (6):604-608. doi:10.1097/JTO.0b013e318170fca4

32. Devereaux PJ, Szczeklik W. Myocardial injury after non-cardiac surgery: diagnosis and management. Eur Heart J. 2019. doi:10.1093/eurheartj/ehz301

33. Eldridge SM, Chan CL, Campbell MJ, et al. CONSORT 2010 statement: extension to randomised pilot and feasibility trials. BMJ. 2016;355:i5239. doi:10.1136/bmj.i5239

34. Chapman CR, Zaslansky R, Donaldson GW, Shinfeld A. Postoperative pain trajectories in cardiac surgery patients. Pain Res Treat. 2012;2012:608359.

35. Thabane L, Ma J, Chu R, et al. A tutorial on pilot studies: the what, why and how. BMC Med Res Methodol. 2010;10:1. doi:10.1186/ 1471-2288-10-1

36. Julious SA. Sample size of 12 per group rule of thumb for a pilot study. Pharmaceut Statist. 2005;4(4):287-291. doi:10.1002/(ISSN)1539-1612

37. Gauthier S, Herrmann N, Ferreri F, Agbokou C. Use of memantine to treat Alzheimer's disease. CMAJ. 2006;175(5):501-502. doi:10.1503/ cmaj. 1060168
38. Ebixa. Ebixa product monograph: lundbeck. Available from: https:// www.lundbeck.com/au/products/our-products/ebixa. Accessed January 31, 2020.

39. Pharmascience Inc. pms-Memantine product monograph 2016. Available from: https://pdf.hres.ca/dpd_pm/00034930.PDF. Accessed January $31,2020$.

40. Onugha O, Ivey R, McKenna R. Novel techniques and approaches to minimally invasive thoracic surgery. Surg Technol Int. 2017;30:231-235.

41. Kadam RA, Borde SU, Madas SA, Salvi SS, Limaye SS. Challenges in recruitment and retention of clinical trial subjects. Perspect Clin Res. 2016;7(3):137-143. doi:10.4103/2229-3485.184820

42. Gul RB, Ali PA. Clinical trials: the challenge of recruitment and retention of participants. J Clin Nurs. 2010;19(1-2):227-233. doi:10.1111/j.1365-2702.2009.03041.x

43. Thoma A, Farrokhyar F, McKnight L, Bhandari M. Practical tips for surgical research: how to optimize patient recruitment. Can J Surg. 2010;53(3):205-210

44. Freixinet JL, Canalis E, Julia G, Rodriguez P, Santana N, Rodriguez de Castro F. . Axillary thoracotomy versus videothoracoscopy for the treatment of primary spontaneous pneumothorax. Ann Thorac Surg. 2004;78(2):417-420. doi:10.1016/j.athoracsur.2003.11.038

45. Gerbershagen HJ, Pogatzki-Zahn E, Aduckathil S, et al. Procedurespecific risk factor analysis for the development of severe postoperative pain. Anesthesiology. 2014;120(5):1237-1245. doi:10.1097/ ALN.0000000000000108

46. Bendixen M, Jorgensen OD, Kronborg C, Andersen C, Licht PB. Postoperative pain and quality of life after lobectomy via video-assisted thoracoscopic surgery or anterolateral thoracotomy for early stage lung cancer: a randomised controlled trial. Lancet Oncol. 2016;17(6):836-844. doi:10.1016/S1470-2045(16)00173-X

47. Tighe PJ, Le-Wendling LT, Patel A, Zou B, Fillingim RB. Clinically derived early postoperative pain trajectories differ by age, sex, and type of surgery. Pain. 2015;156(4):609-617. doi:10.1097/01.j. pain.0000460352.07836.0d

48. Okamoto A, Yamasaki M, Yokota I, et al. Classification of acute pain trajectory after breast cancer surgery identifies patients at risk for persistent pain: a prospective observational study. J Pain Res. 2018;11:2197-2206. doi:10.2147/JPR

49. Anwar S, Cooper J, Rahman J, Sharma C, Langford R. Prolonged perioperative use of pregabalin and ketamine to prevent persistent pain after cardiac surgery. Anesthesiology. 2019;131(1):119-131. doi:10.1097/ALN.0000000000002751

50. Rosenthal R, Kasenda B, Dell-Kuster S, et al. Completion and publication rates of randomized controlled trials in surgery: an empirical study. Ann Surg. 2015;262(1):68-73. doi:10.1097/SLA.0000000000000810
Journal of Pain Research

\section{Publish your work in this journal}

The Journal of Pain Research is an international, peer reviewed, open access, online journal that welcomes laboratory and clinical findings in the fields of pain research and the prevention and management of pain. Original research, reviews, symposium reports, hypothesis formation and commentaries are all considered for publication. The manuscript

Submit your manuscript here: https://www.dovepress.com/journal-of-pain-research-journal management system is completely online and includes a very quick and fair peer-review system, which is all easy to use. Visit http:// www.dovepress.com/testimonials.php to read real quotes from published authors. 